\title{
Improvement in Analytical Methods for Determination of Sugars in Fermented Alcoholic Beverages
}

\author{
Ayalew Debebe, ${ }^{1,2}$ Shibru Temesgen, ${ }^{3}$ Mesfin Redi-Abshiro ${ }^{1 D},^{1}$ \\ Bhagwan Singh Chandravanshi ${ }^{\circ},{ }^{1}$ and Estifanos Ele ${ }^{1}$ \\ ${ }^{1}$ Department of Chemistry, Addis Ababa University, P.O. Box 1176, Addis Ababa, Ethiopia
${ }^{2}$ Department of Chemistry, Haramaya University, P.O. Box 138, Dire Dawa, Ethiopia
${ }^{3}$ Department of Statistics, Addis Ababa University, P.O. Box 1176, Addis Ababa, Ethiopia
}

Correspondence should be addressed to Mesfin Redi-Abshiro; mesfin.redi@aau.edu.et

Received 27 April 2018; Revised 21 June 2018; Accepted 5 July 2018; Published 8 October 2018

Academic Editor: Hana Sklenarova

Copyright (c) 2018 Ayalew Debebe et al. This is an open access article distributed under the Creative Commons Attribution License, which permits unrestricted use, distribution, and reproduction in any medium, provided the original work is properly cited.

\begin{abstract}
The main objective of this study was to improve the performance of analytical methods for the determination of sugars in fermented alcoholic beverages based on mid-infrared-partial least squares (MIR-PLS), high-performance liquid chromatography with the ultraviolet detector (HPLC-UV), high-performance liquid chromatography with the refractive index detector (HPLCRI), and sulfuric acid methods. The MIR-PLS method was found to give good prediction of individual sugars: glucose, fructose, sucrose, and maltose in the alcoholic beverages with less than $4 \%$ error. The HPLC-UV method can be used for the determination of glucose in alcoholic beverages after derivatization with $p$-aminobenzoic acid ethyl ester. The HPLC-RI method was found to be applicable for the determination of individual sugars: glucose, fructose, sucrose, and maltose in the alcoholic beverages. The limit of detection (\%, w/w) and recovery (\%) of the individual sugars by the HPLC-RI method were fructose 0.001, 89.4-106; glucose $0.002,92.4-109$; and sucrose $0.002,94.2-95.1$. The sulfuric acid method was found to be useful for the determination of total sugar in the alcoholic beverages. The limit of detection $(\%, w / w)$ and recovery $(\%)$ of the total sugar by the sulfuric acid method were found to be $0.009,98.2-109$. The HPLC-RI method was applied to determine the level of individual sugars, while the sulfuric acid method was used to determine total sugar in Ethiopian traditional fermented alcoholic beverages: Tella, Netch Tella, Filter Tella, Borde, Tej, Korefe, Keribo, and Birz. The sugar contents in the real samples were found in the ranges (\%): glucose 0.07-5.60, fructose 0.09-8.50, sucrose and maltose 0.08-3.00, and total sugar 12.0-64.5. The levels of sugars in Ethiopian traditional fermented alcoholic beverages were found to be comparable with literature data.
\end{abstract}

\section{Introduction}

Carbohydrates are one of the most abundant compounds in foods [1-6]. They are classified into five major classes, which are monosaccharides, disaccharides, oligosaccharides, polysaccharides, and nucleotides [7]. Mono- and disaccharides with a sweet flavor are commonly called sugars [8].

Alcoholic beverages contain sugars and other soluble solids [9]. In beverages, especially in beer, $80-85 \%$ of nonvolatile materials (30-40 g/L) are sugars [10]. Fructose, glucose, maltose, sucrose, and maltotriose (but not lactose) are fermentable sugars [10]. However, oligosaccharides containing more than three glucose units cannot be fermented [10]. Thus, when fermentation is completed, only small amounts of lower sugars are found in alcoholic beverages [10].

The determination of sugars in alcoholic beverages has been reported using a large number of analytical techniques such as chromatographic techniques, spectroscopic techniques, colorimetric methods, iodometric methods, and enzymatic techniques [11]. Iodometric methods [11] and traditional colorimetric methods [12] are unable to quantitate sugars individually. Chromatography and capillary electrophoresis methods require derivatization (indirect method) because carbohydrates are nonvolatile $[1,13]$ and lack both charge and strong chromophore [11]. Although 
derivatization provides high sensitivity, it is complicated and time-consuming [11]. Both gas and liquid chromatographic techniques have used different derivatizing reagents. For gas chromatography, trimethylsilyl (TMS) ethers are the most popular derivatizing agent [14]. However, TMS derivatization has limitations such as it is unstable, forms multiple peaks, and has difficulty in preparation $[13,14]$. Likewise, among different UV active and fluorophorederivatizing agents, $p$-aminobenzoic acid ethyl ester (ABEE) is the most widely known one [1]. The derivatization of reducing sugars with $\mathrm{ABEE}$ is easy and required no special equipment; moreover, the method showed higher sensitivity and elimination of the possible doublet that could be formed by mutarotation of the free reducing end of sugars [1]. In the direct method, high-performance liquid chromatography (HPLC) has been used with pulsed amperometric, evaporative light-scattering, and refractive index detectors [1, 15] and ultraviolet detectors at $195 \mathrm{~nm} \mathrm{[3].} \mathrm{A} \mathrm{direct} \mathrm{method} \mathrm{with}$ the sugar-borate complex using capillary zone electrophoresis (CZE) has been used. However, it takes about $20 \mathrm{~min}$ to analyze several carbohydrates because the sugar-borate complexes migrate against the direction of the EOF [11]. Chromatographic methods have high accuracy, but they are often time-consuming, labor intensive, and require tedious and complex processing. Recently, near-infrared (NIR) and middle-infrared (MIR) spectrometries have become popular. They have been applied in a low-cost, rapid, and nondestructive way [16]. However, different techniques have their own advantages and disadvantages.

The determination of sugars in alcoholic beverages has considerable importance $[1-4,17,18]$. It is useful to know the contribution of sugars to flavor and sensory characteristics to evaluate their nutritive (caloric) value [1], to evaluate how they are formed and assimilated [10], and to know their health impacts [19].

The literature survey revealed that only a few studies have been conducted on the determination of chemical composition of Ethiopian traditional fermented beverages. These include determination of phenolics [20], alcohol contents [21-23], and minerals [24]. However, no study has been reported on the sugar contents of traditional fermented beverages.

Therefore, the objectives of this study are (i) to develop new analytical methods for the determination of sugars in fermented alcoholic beverages based on mid-infrared-partial least squares (MIR-PLS), high-performance liquid chromatography with the refractive index detector (HPLC-RI), high-performance liquid chromatography with the ultraviolet detector (HPLC-UV), and sulfuric acid methods, (ii) to compare the analytical parameters of the newly developed methods, and (iii) to determine the level of sugars in Ethiopian traditional fermented alcoholic beverages: Tella, Netch Tella, Filter Tella, Borde, Tej, Korefe, Keribo, and Birz.

\section{Materials and Methods}

2.1. Instrumentation. UV-Vis spectrophotometer (Lambda 950; PerkinElmer, UK) with a $1 \mathrm{~cm}$ path length quartz $\mathrm{cu}-$ vette was used to determine total carbohydrates. The
Fourier-transform infrared spectrometer (Spectra 65; PerkinElmer, UK) with $\mathrm{ZnSe}$ window as a sample holder, and HPLC-UV and HPLC-RI (Agilent Technologies, Germany) were used for the determination of individual sugars.

2.2. Reagents and Chemicals. Ethanol (99.99\%; Fisher Scientific, UK), glucose (laboratory reagent; Merck Extra Pure, England), fructose (laboratory reagent; Pharmacos Ltd, England), sucrose (analytical reagent; Guangdong Guanghua Chemical Factory Co. Ltd, China), and maltose (laboratory reagent; The British Drug Houses Ltd, Poole, England) were used to prepare synthetic calibration and validation sets. $p$-Amino benzoic acid ethyl ester (ABEE) (Riedel-de Haen AG, Seelze, Hanover, Germany), acetic acid (99.5\%; BDH Chemicals Ltd, Poole, England), and sodium borohydride (BDH Chemicals Ltd, Poole, England) were used for derivatizing sugars. Sulfuric acid (Sigma-Aldrich, Germany) was used for the determination of total carbohydrate. Chloroform (Carlo Erba Reagents, France) was used for purifying the derivatized compound. Distilled deionized water was used for the preparation of standards and dilution of samples.

2.3. Preparation of Standard Solutions. Calibration and validation sets were prepared by mixing ethanol with sugars for sugar determination with ethanol standards by the MIRPLS method. The compositions of the standards were ethanol $(2-12 \%, w / w)$, fructose $(0-5 \%, w / w)$, glucose $(0-5 \%$, $\mathrm{w} / \mathrm{w})$, sucrose $(0-5 \%, \mathrm{w} / \mathrm{w})$, and maltose $(0-5 \%, \mathrm{w} / \mathrm{w})$, whereas for sugar standards without ethanol, the compositions of the standards were glucose $(0-14.2 \%$, w/w), fructose $(0-17.3 \%, \mathrm{w} / \mathrm{w})$, sucrose $(0-23.4 \%, \mathrm{w} / \mathrm{w})$, and maltose $(0-15.01 \%, \mathrm{w} / \mathrm{w})$.

For the HPLC-RI method, average calibration curves were developed with standard solutions of glucose, fructose, and sucrose from $0.03 \%(\mathrm{w} / \mathrm{w})$ to $0.2 \%(\mathrm{w} / \mathrm{w})$.

For the HPLC-UV method, the average calibration curve was constructed with standard solutions of glucose from 0.0002 to $0.002 \mathrm{mg} / \mathrm{L}$ which were derivatized using ABEE.

For the sulfuric acid method, the average calibration curve was constructed with the series of glucose standard solutions in the range $0.01-0.1 \mathrm{~g} / \mathrm{L}$.

2.4. Sampling and Sample Preparation. Eight most popular Ethiopian traditional fermented beverages, Tej (honey wine), Tella (a malt beverage like beer), Korefe, Keribo, Birz, Netch Tella, Filter Tella, and Borde, were selected for this study. A total of 57 samples: 15 Tej, 15 Tella, 6 Korefe, 6 Keribo, 4 Birz, 4 Netch Tella, 4 Filter Tella, and 3 Borde, were collected randomly from vending houses at different subcities of Addis Ababa (Ethiopia) and nearby towns (Sebeta, Dukem, Sululta, Sendafa, and Burayu) of Oromia Regional State. The characteristics of alcoholic samples (the $\mathrm{pH}$ value and ethanol content) and brief information about raw materials and processes used for the production of Ethiopian traditional fermented beverages are given in Table 1 . A $500 \mathrm{~mL}$ aliquot of each type of the beverages was collected from the 
TABle 1: Physicochemical properties, raw materials, and production process of some Ethiopian traditional alcoholic beverages.

\begin{tabular}{|c|c|c|c|c|}
\hline S. no. & $\begin{array}{c}\text { Samples } \\
(\% \text { alcohol })^{*}\end{array}$ & $\begin{array}{l}\text { Physicochemical } \\
\text { properties }\end{array}$ & Raw materials & Production process \\
\hline 1 & $\begin{array}{l}\text { Tella }(2.9 \pm 0.3) \\
\text { Korefe }(4.6 \pm 0.4)\end{array}$ & $\begin{array}{c}\text { Dark brown in color, with } \\
\text { pH } 3.56 \pm 0.02 \text { and } 4.28 \pm \\
0.02\end{array}$ & $\begin{array}{c}\text { Kita (a thin, } 5-10 \mathrm{~mm} \text { thick, pancake-like } \\
\text { bread), enkuro (a dark brown toasted } \\
\text { flour), bikil (germinated grain), and } \\
\text { powdered gesho (Rhamnus prinoides) } \\
{[25,26]}\end{array}$ & $\begin{array}{l}\text { A four-phase fermentation for } \\
\qquad 10-12 \text { days }[25,26]\end{array}$ \\
\hline 2 & $\operatorname{Tej}(9.1 \pm 0.3)$ & $\begin{array}{l}\text { Yellow, sweet, } \\
\text { effervescent, and cloudy, } \\
\text { with pH } 3.65 \pm 0.01\end{array}$ & $\begin{array}{c}\text { Honey or mixture of sugar with honey and } \\
\text { leaves of gesho (Rhamnus prinoides) } \\
{[25,27]}\end{array}$ & $\begin{array}{l}\text { Mixing boiled must with gesho } \\
\text { (Rhamnus prinoides) and } \\
\text { unboiled must and then allowing } \\
\text { to ferment for } 5 \text { days in warm } \\
\text { weather or for } 15-20 \text { days in } \\
\text { colder weather }[25,27]\end{array}$ \\
\hline 3 & $\operatorname{Birz}(6.5 \pm 0.8)$ & $\begin{array}{l}\text { Yellow, sweet, } \\
\text { effervescent, and cloudy, } \\
\text { with pH } 3.40 \pm 0.06\end{array}$ & Honey or mixture of sugar with honey [25] & $\begin{array}{c}\text { Has a short fermentation period, } \\
\text { usually overnight }[25]\end{array}$ \\
\hline 4 & Borde $(1.8 \pm 0.4)$ & $\begin{array}{l}\text { Opaque, effervescent, and } \\
\text { whitish-grey to brown } \\
\text { colored with a thick } \\
\text { consistency and a sweet- } \\
\text { sour taste, with pH } 5.77 \pm \\
0.03\end{array}$ & $\begin{array}{c}\text { Unmalted maize (Zea mays), barley } \\
\text { (Hordeum vulgare), wheat (Triticum } \\
\text { aestivum), finger millet (Eleusine } \\
\text { coracana), sorghum (Sorghum bicolor), } \\
\text { and/or tef (Eragrostis tef) and their malt; } \\
\text { additional ingredients garlic, fresh chili } \\
\text { (Capsicum minimum), ginger, and salt } \\
{[25,28,29]}\end{array}$ & $\begin{array}{l}\text { A four-phase fermentation for } \\
\text { less than } 4 \text { days }[25,28,29]\end{array}$ \\
\hline 5 & Keribo $(1.7 \pm 0.3)$ & $\begin{array}{l}\text { Dark brown colored, with } \\
\text { pH } 3.72 \pm 0.03\end{array}$ & $\begin{array}{l}\text { Unmalted roasted barley (Hordeum } \\
\text { vulgare), sugar, and yeast [30] }\end{array}$ & $\begin{array}{c}\text { Has a short fermentation period, } \\
\text { usually overnight [30] }\end{array}$ \\
\hline
\end{tabular}

*\% alcohol was determined by the method in [22].

three sites of each of the subcities of Addis Ababa and nearby towns. A $1000 \mathrm{~mL}$ bulk sample was prepared for each sample type from one specific sampling site. This was done by taking $333.3 \mathrm{~mL}$ of the beverage from each of the three samples from one place and mixing well in a $1 \mathrm{~L}$ volumetric flask. All the samples were collected using glass amber bottles and kept at $4^{\circ} \mathrm{C}$ until the analysis time. Ethiopian traditional fermented alcoholic beverages are either liquid or semiliquid. The liquid samples such as Tella, Tej, Birz, Netch Tella, Filter Tella, and Keribo were filtered before analysis. The sugars were extracted from the semiliquid samples such as Borde and Korefe by an optimized procedure.

2.5. Derivatization of Sugar for the HPLC-UV Method. The derivatization procedures of sugar with ABEE reported by Gomis et al. [1] and Munegumi and Goto [31] were different. Thus, a modified procedure was used in this study. An ABEE methanol solution $(4 \mathrm{~mL}, 0.5 \mathrm{~g} / \mathrm{mL})$ and glacial acetic acid $(310 \mathrm{~mL})$ were dissolved at $40-50^{\circ} \mathrm{C}$ in a polypropylene tube. A $0.60 \mathrm{~g}$ sodium borohydride was added to the tube, which was sealed with a screw cap and vortexed to give an ABEE stock solution. An aliquot $(2 \mathrm{~mL})$ of the ABEE stock solution and a standard saccharide solution or sample $(500 \mu \mathrm{L})$ were mixed by vortexing, and the resulting solution was heated at $80^{\circ} \mathrm{C}$ for $6 \mathrm{~h}$. After cooling and centrifuging for $1 \mathrm{~min}$, the filtrate was treated with $3 \mathrm{~mL}$ water and centrifuged. Again, the filtrate was treated with chloroform $(2 \times 5 \mathrm{~mL})$. Finally, the upper layer (the aqueous phase) was used for HPLC analysis after filtration using a micromembrane $(0.45 \mathrm{~mm}$ pore size).
2.6. Procedure for Total Sugars. A $1 \mathrm{~mL}$ aliquot of carbohydrate solution was rapidly mixed with $3 \mathrm{~mL}$ of concentrated sulfuric acid in a test tube and vortexed for $30 \mathrm{~s}$. The temperature of the mixture was raised rapidly within $10-15 \mathrm{~s}$ after addition of sulfuric acid. The solution was cooled in ice for $2 \mathrm{~min}$ to bring it to room temperature. Finally, UV light absorption at $315 \mathrm{~nm}$ was measured using a UV spectrophotometer. Reference (reagent blank) solutions were prepared following the same procedure as above, except that the carbohydrate aliquot was replaced with distilled deionized water [12].

\subsection{HPLC Conditions for Indirect (Derivatized)} Determination. The derivatized sample was analyzed to determine the sugars using HPLC with the UV detector at $\lambda_{\max } 230 \mathrm{~nm}$. The chromatographic separation was achieved on a $\mathrm{C}_{18}$ column maintained at $45^{\circ} \mathrm{C}$. A binary solvent system comprising $0.5 \%$ aqueous trifluoroacetic acid as solvent $\mathrm{A}$ and acetonitrile as solvent $\mathrm{B}$ was used under the gradient mode. The gradient condition was $0-5 \mathrm{~min}$ solvent A, 5-10 min $0-20 \%$ B, $10-35$ min $20-25 \%$ B, 35-50 min $25-45 \% \mathrm{~B}$, and $50-60 \mathrm{~min} 45-100 \% \mathrm{~B}$. The mobile-phase flow rate was $0.5 \mathrm{~mL} \cdot \mathrm{min}^{-1}$, and sample injection volume was $3 \mu \mathrm{L}$.

2.8. HPLC Conditions for Direct (Nonderivatized) Determination. The sugar determination was done using HPLC with the RI detector. The chromatographic separation was achieved in the Hi-Plex $\mathrm{H}$ column $(7.7 \times 300 \mathrm{~mm})$ maintained at $35^{\circ} \mathrm{C}$. The solvent used was distilled-deionized 
water. The mobile-phase flow rate and sample injection volumes were $0.5 \mathrm{~mL} \cdot \mathrm{min}^{-1}$ and $10 \mu \mathrm{L}$, respectively.

\section{Results and Discussion}

3.1. Extraction of Sugars. For the extraction of sugars from the semiliquid samples, the types and amounts of the extracting solvent and extraction time were optimized. 80\% $(\mathrm{v} / \mathrm{v})$ methanol, $80 \%(\mathrm{v} / \mathrm{v})$ ethanol, and water were considered as the extracting solvent. Among the solvents checked, $80 \%(\mathrm{v} / \mathrm{v})$ methanol showed better efficiency than others (the data are not presented). The extraction time was varied in the range $30-120 \mathrm{~min}$. The optimum time for extraction of sugars was found to be $90 \mathrm{~min}$. Hence, $90 \mathrm{~min}$ was used to extract sugars from the beverages (Table 2).

3.2. Determination of Individual Sugars Using MIR-PLS. Carbohydrates have strong absorption bands which overlap in the spectral region, $850-1200 \mathrm{~cm}^{-1}$ (Figure 1). This seriously hinders the quantification of individual carbohydrates [32, 33]. Hence, MIR-PLS was proposed as a method for the determination of individual sugars. The $\mathrm{C}-\mathrm{O}$ stretching band in the spectral region $850-1200 \mathrm{~cm}^{-1}$ was selected due to higher sensitivity of the spectra to develop a calibration model [33]. The MIR spectra of selected fermented alcoholic beverages are shown in Figure 2. It can be seen that the MIR spectrum of Korefe resembles very much the spectrum of ethanol given in Figure 1. This is because of relatively low sugar content in the Korefe compared to the sugar content in the Birz and Tej.

Two models using sugars (fructose, sucrose, glucose, and maltose) with and without ethanol were used by modifying Rambla et al. [32] and Leopold et al. [33] models. To determine sugars using the MIR-PLS method, a method without ethanol was chosen to avoid interference. To avoid overfitting, the number of principal components (PCs) was fixed to 6 for glucose, fructose, sucrose, and maltose in the model.

3.3. Pretreatment Methods. In order to find the model with best prediction capacity, PLS regression was applied to different spectra such as raw spectra, first derivative spectra, second derivative spectra, and others. Leopold et al. [33] also applied PLS regression to raw spectra, first derivative spectra, and second derivative spectra. In their study, lower RMSEP values were provided by the first derivative spectra. But in the present study, the second derivative spectra provided the lower RMSEP values (Table 3). This is because the second derivative preprocessing removes background and increases spectral resolution [34]. Hence, the second derivative spectra were used for the prediction of sugar concentration in the alcoholic beverages.

3.4. Method Validation. To avoid concentration data overfitting, the cross-validation method, leaving out one sample at a time, was used. Accordingly, the validation was done using 50 synthetic samples. The obtained validations showed
TABle 2: Optimized extraction time for sugar extraction from semiliquid samples.

\begin{tabular}{lcccc}
\hline $\begin{array}{l}\text { Extraction time } \\
(\mathrm{min})\end{array}$ & 30 & 60 & 90 & 120 \\
\hline $\begin{array}{l}\text { Total carbohydrate } \\
(\mathrm{Glu} \cdot(\mathrm{g} / \mathrm{L}))\end{array}$ & $14.9 \pm 0.1$ & $15.1 \pm 0.1$ & $25.8 \pm 0.2$ & $13.4 \pm 0.2$ \\
\hline
\end{tabular}

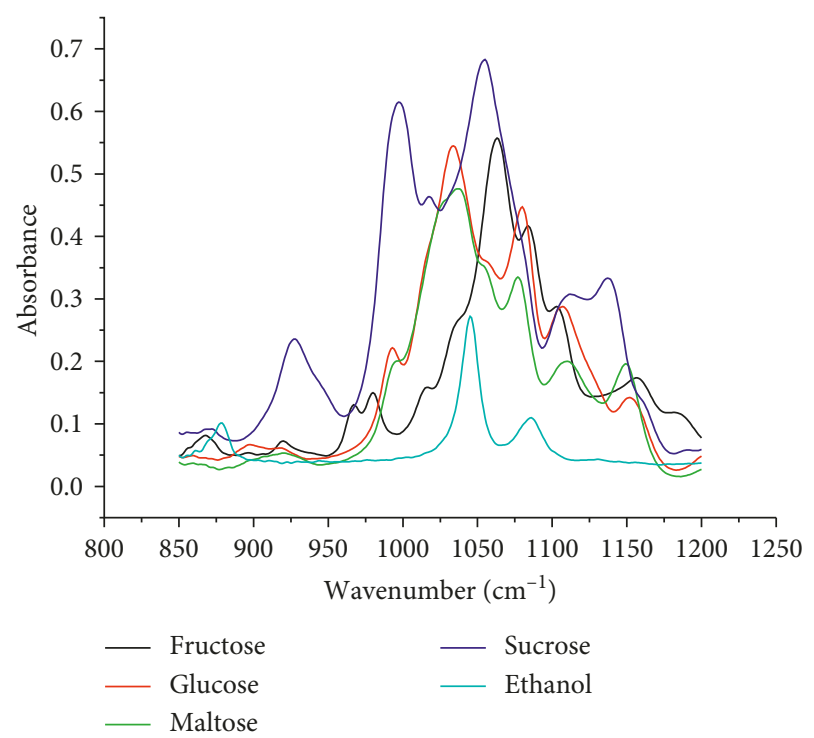

FIgURE 1: MIR spectra of $5 \%(\mathrm{w} / \mathrm{w})$ ethanol and $10 \%(\mathrm{w} / \mathrm{w})$ individual sugars.

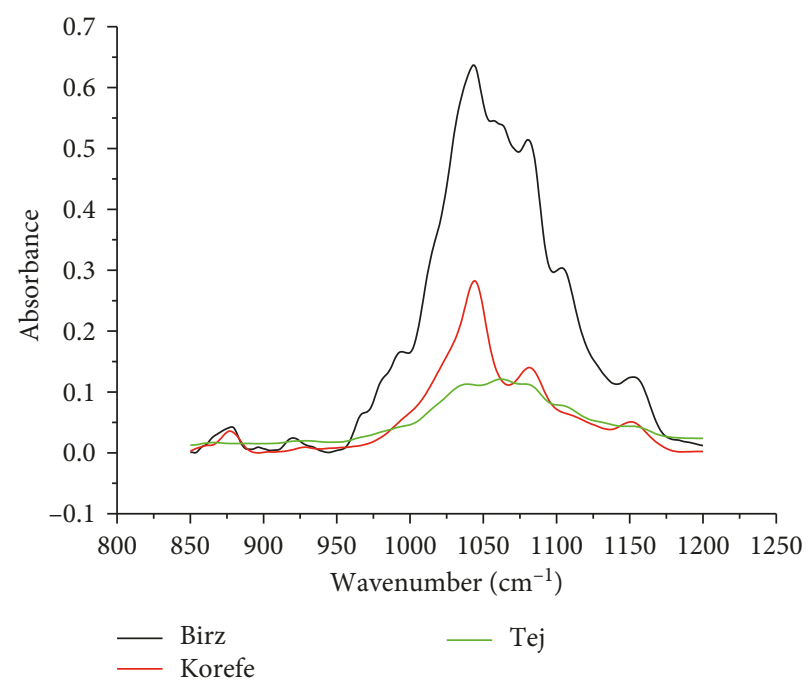

FIGURE 2: MIR spectra of selected fermented alcoholic beverages.

that the PLS calibration model of each has a very good performance (Table 3). It was also found comparable with the report of Irudayaraj and Tewari [35] in terms of correlation $\left(R^{2}\right)$, RMSEP, and the number of factors used. In addition, the predicted amounts were evaluated and compared with the measured values at the $99 \%$ confidence level. Overall, no significant variations were obtained between the measured and predicted amounts. 
TABLE 3: Results of MIR-PLS calibration models for the determination of sugars in alcoholic beverages.

\begin{tabular}{lccccc}
\hline \multirow{2}{*}{ Data treatment } & \multirow{2}{*}{ Analytes } & Principal components & \multicolumn{2}{c}{ Calibration } & \multicolumn{2}{c}{ Validation } \\
& & & $R^{2}$ & RMSEE & $R^{2}$ \\
\hline Second derivative & Glucose & 6 & 0.992 & 0.18 & 0.987 \\
Second derivative & Fructose & 6 & 0.997 & 0.06 & 0.996 \\
Second derivative & Sucrose & 6 & 0.989 & 0.22 & 0.996 \\
Second derivative & Maltose & 6 & 0.999 & 0.04 & 0.95 \\
\hline
\end{tabular}

RMSEE: root mean square error of estimation; RMSEP: root mean square error of prediction.

The correlations between actual and predicted values of the analytes are shown in Figure 3. From the correlation graphs (Figure 3), almost all the curves have shown better correlations. The model was validated in terms of $\%$ error using the following equation:

$$
\% \text { error }=\frac{\text { PLS predicted values }- \text { actual values }}{\text { actual values }} \times 100 \text {. }
$$

The \% error was found in the range $0.21-3.7 \%(3.7 \%$ glucose, $1.1 \%$ fructose, $0.21 \%$ sucrose, and $0.23 \%$ maltose). This showed that the proposed method has less than $4 \%$ error. Thus, the MIR-PLS method was found to give good prediction of sugars in the alcoholic beverages.

3.5. Comparisons of MIR-PLS with HPLC-RI. Comparison of sugar content obtained by MIR-PLS and HPLC-RI was made. The comparison is illustrated in Figure 4. Fructose showed the best comparison, while glucose showed the least comparison among all the sugars. The two techniques were found to be comparable and showed no significance difference at the $95 \%$ confidence level. Hence, MIR-PLS was found to be a promising method for sugar determination in the alcoholic beverages. However, to apply for the analysis of real samples, the samples should be purified from potential interferences such as ethanol, phenolic compounds, proteins, amino acids, and others $[36,37]$.

\subsection{Determination of Individual Sugars with Derivatization} Using HPLC-UV. Carbohydrates lack chromophore [11], and they cannot be detected by the UV detector in the HPLC-UV. Thus, they require derivatization. In this study, the derivatization was done using glucose, fructose, and sucrose with $p$-aminobenzoic acid ethyl ester (ABEE), acetic acid, and sodium borohydride. The imine formation was preceded for aldose, not for ketoses and sucrose. Thus, the obtained results are in agreement with different literature reports $[1,31]$ (Figure 5).

It can be clearly seen in the chromatogram (Figure 5) that only glucose and mixture have peaks at 21 min retention time due to the glucose labeling, while all the chromatograms (a-e) have peaks at $42 \mathrm{~min}$, owing to excess ABEE. The structure of derivatized glucose (the formed compound) is shown in Scheme 1.

Glucose derivatization was further confirmed by ${ }^{1} \mathrm{H}$ NMR and ${ }^{13} \mathrm{C}$ NMR analysis. ${ }^{1} \mathrm{H}$ NMR spectrum of the compound Glu-ABEE showed the presence of four protons on 1,4-disubstituted aromatic ring appearing at $\delta 6.73 \mathrm{ppm}$ $\left(2 \mathrm{H}\right.$ on $\mathrm{C}_{6}$ and $\left.\mathrm{C}_{8} ; J=8.4 \mathrm{~Hz}\right)$ and $7.69 \mathrm{ppm}\left(2 \mathrm{H}\right.$ on $\mathrm{C}_{5}$ and
$\mathrm{C}_{9} ; J=8.4 \mathrm{~Hz}$ ). This suggested that the four protons are on different chemical environments (i.e., two in one and the remaining two in another environment). In addition, based on the $J$ values, they are protons which are coupled. The proton signals between $\delta 3 \mathrm{ppm}$ and $3.6 \mathrm{ppm}$ are due to the protons of $\mathrm{OH}$ glucose. The signals at $\delta 4.2 \mathrm{ppm}\left(2 \mathrm{H}\right.$ on $\mathrm{C}_{2}$; quartet) and $\delta 1.3 \mathrm{ppm}\left(3 \mathrm{H}\right.$ on $\mathrm{C}_{1}$; triplet) are due to $\mathrm{CH}_{2}$ and $\mathrm{CH}_{3}$ of the ester, respectively. The signals at $\delta 2.5 \mathrm{ppm}$ are due to DMSO.

The ${ }^{13} \mathrm{C}$ NMR analyzed with the DEPT-135 spectrum revealed the presence of three quaternary (from the benzene ring at $\delta 152 \mathrm{ppm}\left(\mathrm{C}_{7}\right)$ and $\delta 118 \mathrm{ppm}\left(\mathrm{C}_{4}\right)$ and from the carboxyl group of ester at $\left.\delta 166 \mathrm{ppm}\left(\mathrm{C}_{3}\right)\right)$ and three methylene carbon atoms (at $\delta 59.94 \mathrm{ppm}\left(\mathrm{C}_{10}\right), \delta 60.14 \mathrm{ppm}$ $\left(\mathrm{C}_{15}\right)$, and $\left.\delta 60.95 \mathrm{ppm}\left(\mathrm{C}_{2}\right)\right)$. The signal at $\delta 112\left(\mathrm{C}_{6}\right.$ and $\left.\mathrm{C}_{8}\right)$ and $\delta 131\left(\mathrm{C}_{5}\right.$ and $\left.\mathrm{C}_{9}\right)$ was from methine carbons of the ring. The ${ }^{13} \mathrm{C}$ NMR signals at $\delta 76 \mathrm{ppm}\left(\mathrm{C}_{11}\right), 74.69 \mathrm{ppm}\left(\mathrm{C}_{12}\right)$, $70.42 \mathrm{ppm}\left(\mathrm{C}_{13}\right)$, and $84.98 \mathrm{ppm}\left(\mathrm{C}_{14}\right)$ were from the $\mathrm{Cs}$ of the glucose part. The signal at $\delta 14.78 \mathrm{ppm}\left(\mathrm{C}_{1}\right)$ was from the methyl of the ester group. Moreover, the absence of signal around $\delta=100 \mathrm{ppm}$ confirmed that the glucose ring was opened and further reaction occurred. Thus, the ${ }^{1} \mathrm{H}$ NMR and ${ }^{13} \mathrm{C}$ NMR spectra of the compound confirmed that the derivatization has occurred.

HPLC chromatogram and NMR data confirmed that the labeling is only for glucose. Therefore, only glucose can be determined. To construct a calibration curve, a series of glucose standards from $0.0002 \mathrm{mg} / \mathrm{L}$ to $0.002 \mathrm{mg} / \mathrm{L}$ were prepared in triplicate. Accordingly, the average calibration equation $y=6.41 \times 10^{5} x-84$ (where $y=$ peak area and $x=$ glucose in $\mathrm{g} / \mathrm{mL}$ ) with $R^{2}=0.9997$ was obtained. Therefore, for the determination of glucose, this alternative approach was chosen for two reasons. First, the reducing agent $\mathrm{NaBH}_{4}$ is less toxic and easily available than the usual reducing agent $\mathrm{NaBH}_{3} \mathrm{CN}$, and second, the method has a wider linear range and better correlation.

\subsection{Determination of Sugars Using HPLC-RI and Sulfuric Acid} Method. The chromatograms of sugars and ethanol are illustrated in Figure 6. For the determination of sugars in the real samples, peak identifications were made in the same chromatographic system by comparing each peak's retention time $\left(t_{\mathrm{R}}\right)$ with the reference (standards) and by spiking the sample with the standards. Standards solutions of $0.03-0.2 \%(\mathrm{w} / \mathrm{w})$ for glucose, fructose, and sucrose and standards solution of $0.01-0.1 \mathrm{~g} / \mathrm{L}$ for the total sugars were prepared in triplicate. The calibration equations $y=1.87 \times 10^{6} x+1012, y=2.02 \times 10^{6} x-1836$, and $y=2.00 x$ +2241 (where $y=$ peak area and $x=$ concentration of 


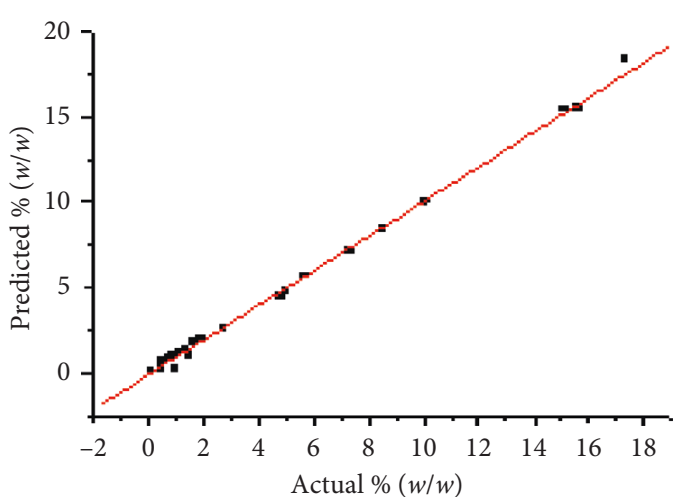

(a)

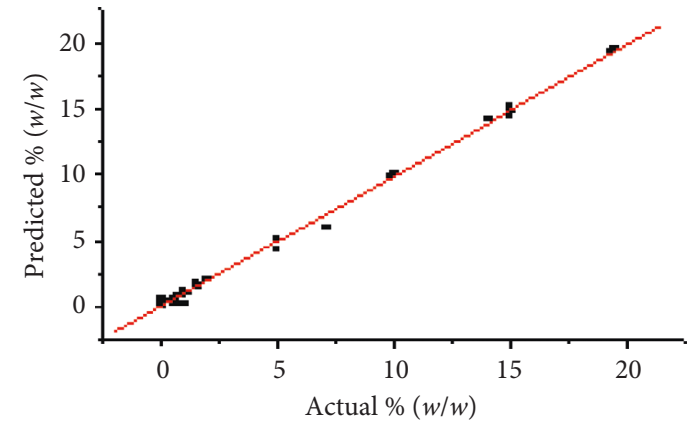

(c)

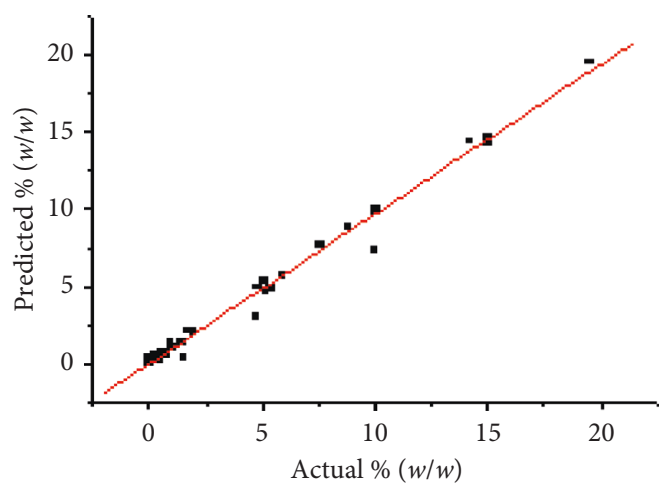

(b)

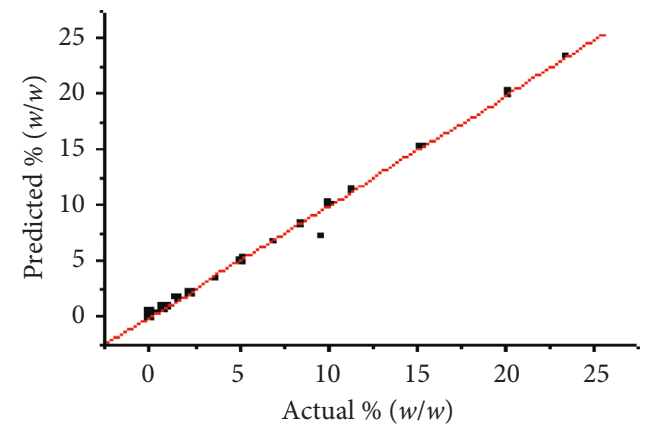

(d)

Figure 3: Correlation statistics between actual and predicted values for fructose (a), glucose (b), maltose (c), and sucrose (d).

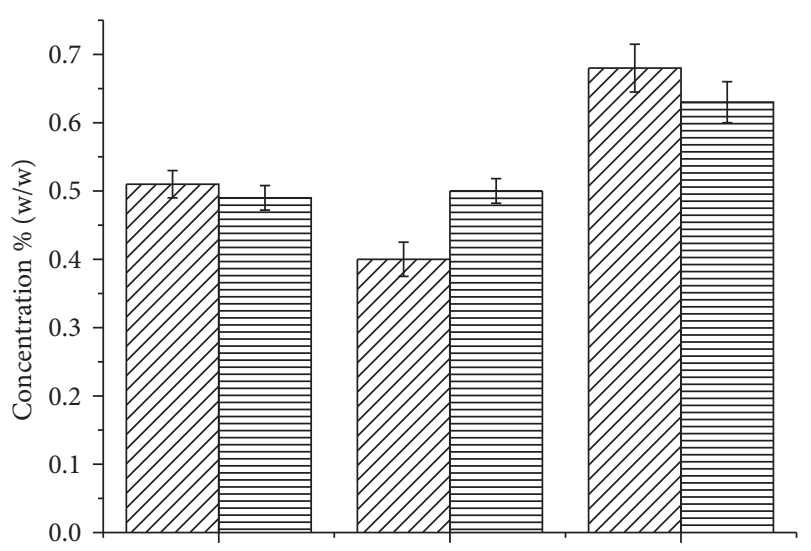

Fructose in mixture Glucose in mixture Sucrose in mixture Synthetic mixture samples

שIn MIR-PLS $\rightleftharpoons$ HPLC-RI

FIgUre 4: Comparison of MIR-PLS with HPLC-RI.

analytes in $\%(\mathrm{w} / \mathrm{w}))$ were assigned for fructose, glucose, and sucrose, respectively. The calibration equation used for the total sugars was $y=10.6 x-0.022$ (where $y=$ peak height and $x=$ glucose concentration in $\mathrm{g} / \mathrm{L})$.

3.8. Method Validation. The proposed method was validated using the recovery test. For recovery determination of fructose, glucose, and sucrose, 0.05 and $0.1 \%(\mathrm{w} / \mathrm{w})$ from each type were spiked. But for the recovery determination of total sugars, 6.5 and $13.0 \mathrm{~g} / \mathrm{L}$ glucose were spiked. The results are presented in Table 4 . LOD $=3 \sigma$ of the residues $(y$ intercepts)/slope [38] was also determined and given in Table 4 . The recovery percentages obtained for fructose (89-106\%), glucose (92-109\%), sucrose (94-95\%), and total carbohydrate (98-109\%) are in the acceptable ranges. This implies that the matrix effects of the samples were not considerable. Therefore, the proposed techniques are appropriate to quantify individual and total sugar contents in the fermented alcoholic beverages.

3.9. Comparison of Advantages and Disadvantages of the Four Methods. In this study, four methods (MIR-PLS, HPLCUV, HPLC-RI, and sulfuric acid methods) have been developed for the determination of sugars in the fermented alcoholic beverages. A comparison has been made on the advantages and disadvantages of the individual methods, and the results are summarized in Table 5. The MIR-PLS method is applicable to determine individual sugars: glucose, fructose, sucrose, and maltose, with good precision and accuracy. But the method suffers from interferences from ethanol, phenolic compounds, proteins, amino acids, and others. The HPLC-UV method is only applicable to determine glucose but not other individual sugars. It also requires derivatization which is time-consuming. The HPLC-RI method is applicable to determine individual sugars: glucose, fructose, and sucrose, without the matrix effect but not other individual sugars. The sulfuric acid method is applicable to determine total sugars with good 


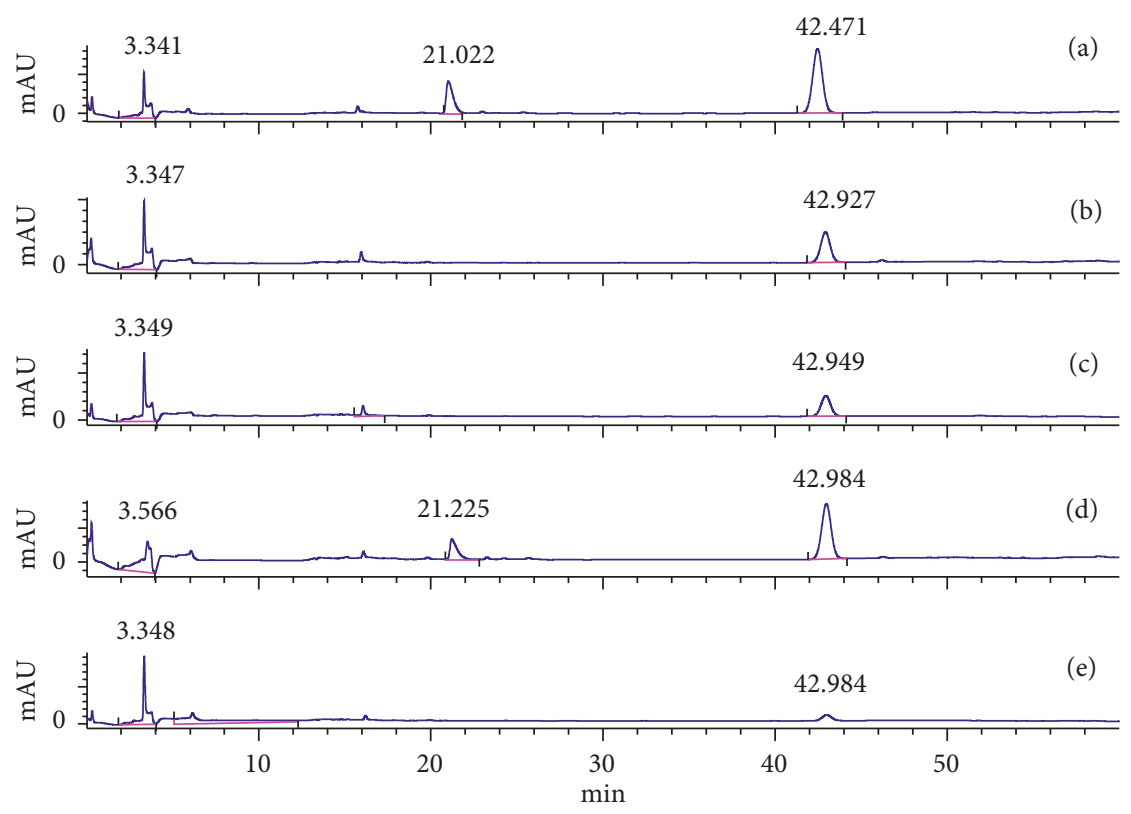

FIgure 5: Chromatograms of sugar derivatives: (a) glucose, (b) fructose, (c) sucrose, (d) mixture, and (e) ABEE.<smiles>O=C(OCI)c1ccc(NCC(O)=C(O)C(O)C(O)CO)cc1</smiles>

Scheme 1: The structure of derivatized glucose.

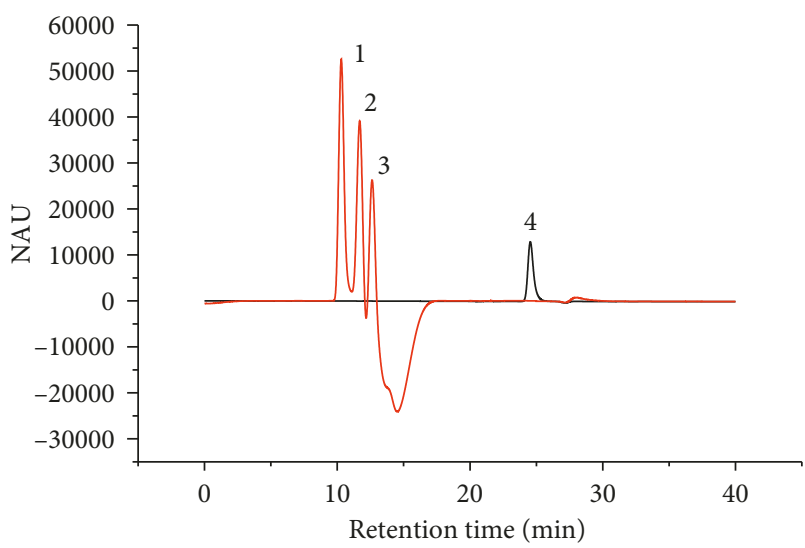

Figure 6: Chromatograms of the mixture of sugars and ethanol: $1=$ sucrose, 2 = glucose, 3 = fructose, and 4 = ethanol. Column: HiPlex H $7.7 \times 300 \mathrm{~mm}$ ID $\left(35^{\circ} \mathrm{C}\right)$. Mobile phase: water. Flow rate: $0.5 \mathrm{~mL} / \mathrm{min}$. Injection volume: $10 \mu \mathrm{L}$.

precision and accuracy. However the method is not applicable to determine individual sugars.

3.10. Analysis of Real Samples. The amounts of sugars found in the real samples (fermented alcoholic beverages) are presented in Table 6 . The amounts of individual sugars are expressed as \% (w/w) and the total sugar as g/L in Ethiopian traditional fermented alcoholic beverages. This is because in the literature, the individual sugar contents are expressed as $\%(w / w)$ and the total sugar content as $\mathrm{g} / \mathrm{L}$ to make the comparison of results of the present study with the results reported in the literature meaningful. The order of the beverages based on the total sugar contents (in g/L) was Birz $>$ Tej $>$ Keribo $>$ Korefe $>$ Netch Tella $>$ Filter Tella $>$ Tella $>$ Borde. Birz and Tej were found to be the leading ones. Particularly for Birz, it is mainly by the unfermented sugars left after fermentation. In Tej, additional honey was added, while it is ready to serve. For the rest of the beverage types, the major reason of variation is the differences in the composition of the raw materials (Table 1) and fermentation time used [25, 30].

Although it is not reasonable to compare beverages of different types, the comparisons were done without considering the factors that can influence their levels of sugars. In this study, Birz was the first in the levels of glucose and fructose, while Keribo was the first in the level of sucrose. Both controlled Tella and Tej have comparable glucose, fructose, and sucrose with the average values of the corresponding samples. However, there were still variations among beverages. This showed that the variation in the composition of the raw materials, preparation process, and fermentation time used (Table 1) are the crucial factors for the difference in the level of sugars in the traditional fermented beverages.

The total sugar contents with average values of $37.0 \mathrm{~g} / \mathrm{L}$ in nonalcoholic beer [39], $42.1 \mathrm{~g} / \mathrm{L}$ in alcoholic beer [39], $90.2 \mathrm{~g} / \mathrm{L}$ in wort from phases I-V [40], and $6.75 \mathrm{~g} / \mathrm{L}[41]$ and $48.8 \mathrm{~g} / \mathrm{L}$ [42] in wine were reported. The Ethiopian traditional fermented alcoholic beverages have been found to contain less sugar than in wort [40] and beer [39] except 
TABLE 4: Limit of detection and recovery percentage for individual sugars by the HPLC-RI method and for total sugar by the sulfuric acid method.

\begin{tabular}{|c|c|c|c|c|c|c|c|c|c|}
\hline \multirow{2}{*}{ S. no. } & \multirow{2}{*}{ Sample } & \multicolumn{2}{|c|}{ Fructose } & \multicolumn{2}{|c|}{ Glucose } & \multicolumn{2}{|c|}{ Sucrose } & \multicolumn{2}{|c|}{ Total sugar } \\
\hline & & $\operatorname{LOD}(\%, w / w)$ & Recovery (\%) & $\operatorname{LOD}(\%, w / w)$ & Recovery (\%) & $\operatorname{LOD}(\%, \mathrm{w} / \mathrm{w})$ & Recovery (\%) & LOD $(\mathrm{g} / \mathrm{L})$ & Recovery (\%) \\
\hline 1 & Keribo & 0.001 & 106 & 0.002 & 93.2 & 0.002 & 94.3 & 0.009 & 98.2 \\
\hline 2 & $T e j$ & 0.001 & 89.4 & 0.002 & 109 & 0.002 & 94.2 & 0.009 & 100 \\
\hline 3 & Tella & 0.001 & 90.3 & 0.002 & 92.4 & 0.002 & 95.1 & 0.009 & 109 \\
\hline
\end{tabular}

TABle 5: Comparison of advantages and disadvantages of the four newly developed methods for the determination of sugars in the fermented alcoholic beverages.

\begin{tabular}{|c|c|c|}
\hline Method & Advantages & Disadvantages \\
\hline MIR-PLS method & $\begin{array}{l}\text { The method is applicable to determine individual } \\
\text { sugars: glucose, fructose, sucrose, and maltose, with } \\
\text { good precision and accuracy. }\end{array}$ & $\begin{array}{l}\text { To apply for the analysis of real samples, the samples } \\
\text { should be purified from potential interferences such } \\
\text { as ethanol, phenolic compounds, proteins, amino } \\
\text { acids, and others. }\end{array}$ \\
\hline HPLC-UV method & $\begin{array}{l}\text { The method is applicable to determine glucose, and it } \\
\text { has a wider linear range and better correlation. }\end{array}$ & $\begin{array}{l}\text { The method is not applicable to determine individual } \\
\text { sugars except glucose, and it requires derivatization } \\
\text { which is time-consuming. }\end{array}$ \\
\hline HPLC-RI method & $\begin{array}{c}\text { The method is applicable to determine individual } \\
\text { sugars: glucose, fructose, and sucrose, without the } \\
\text { matrix effect. }\end{array}$ & $\begin{array}{c}\text { The method is applicable to determine individual } \\
\text { sugars: glucose, fructose, and sucrose, but not other } \\
\text { sugars. }\end{array}$ \\
\hline Sulfuric acid method & $\begin{array}{l}\text { The method is applicable to determine total sugar } \\
\text { (carbohydrate) with good precision and accuracy. }\end{array}$ & $\begin{array}{c}\text { The method is not applicable to determine individual } \\
\text { sugars. }\end{array}$ \\
\hline
\end{tabular}

TABLE 6: The amount of sugars found in Ethiopian traditional fermented alcoholic beverages (individual sugars (\%, w/w) by the HPLC-RI method and total sugar ( $\mathrm{g} / \mathrm{L}$ ) by the sulfuric acid method).

\begin{tabular}{|c|c|c|c|c|c|c|}
\hline \multirow{2}{*}{ S. no. } & \multirow{2}{*}{ Beverage types } & \multirow{2}{*}{ Number } & \multicolumn{3}{|c|}{ Concentration of individual sugars $(\%, w / w)$} & \multirow{2}{*}{ Total carbohydrate $(\mathrm{g} / \mathrm{L})$} \\
\hline & & & Fructose & Glucose & Sucrose and maltose & \\
\hline 1 & Tella & 15 & $0.09 \pm 0.12$ & $0.07 \pm 0.09$ & $0.08 \pm 0.12$ & $12.0 \pm 4.9$ \\
\hline 2 & $T e j$ & 15 & $2.98 \pm 1.10$ & $1.66 \pm 0.60$ & $0.19 \pm 0.20$ & $64.5 \pm 24$ \\
\hline 3 & Korefe & 6 & $0.30 \pm 0.10$ & $0.43 \pm 0.30$ & $0.18 \pm 0.15$ & $34.4 \pm 13.5$ \\
\hline 4 & Keribo & 6 & $0.10 \pm 0.05$ & $0.60 \pm 0.03$ & $3.00 \pm 0.30$ & $50.0 \pm 9.1$ \\
\hline 5 & Birz & 4 & $8.50 \pm 0.50$ & $5.60 \pm 1.40$ & $1.00 \pm 0.70$ & $131 \pm 18$ \\
\hline 6 & Borde & 3 & $0.09 \pm 0.01$ & $4.33 \pm 0.01$ & $0.40 \pm 0.01$ & $11.3 \pm 1.25$ \\
\hline 7 & Netch Tella & 4 & $0.70 \pm 1.33$ & $0.79 \pm 1.35$ & $0.08 \pm 0.03$ & $23.3 \pm 2.8$ \\
\hline 8 & Filter Tella & 4 & $1.40 \pm 2.70$ & $0.90 \pm 1.60$ & $0.36 \pm 0.60$ & $19.0 \pm 4.1$ \\
\hline 9 & Control Tella & 3 & $0.04 \pm 0.01$ & $0.03 \pm 0.01$ & $0.12 \pm 0.01$ & $102 \pm 1.8$ \\
\hline 10 & Control Tej & 3 & $1.77 \pm 0.05$ & $1.11 \pm 0.04$ & $0.14 \pm 0.01$ & $270 \pm 5.7$ \\
\hline
\end{tabular}

Birz, Tej, and Korefe. But they have higher sugar than that reported by Matsuhiro et al. [41].

In some beverages, the concentration of glucose, fructose, and sucrose was reported. The concentration values of sucrose, glucose, and fructose were found in the ranges: $1-3.28$ and $0-10.5,0.13-2.17$ and $0-6.9$, and $0.3-3.72$ and $0-6.7 \%(w / w)$, respectively, in flavored water and soft drinks, respectively $[43,44]$. Since both the flavored water and soft drinks are not fermented beverages, their sugar contents are expected to be higher than those in fermented beverages. Even though the Ethiopian traditional fermented beverages have passed through some extent of fermentation, the obtained results confirmed that the Ethiopian fermented alcoholic beverages have comparable sugar content with that in the nonfermented beverages.

\section{Conclusion}

Improvement in the performance of analytical methods for the determination of sugars in alcoholic beverages using MIR-PLS, HPLC-UV with a derivatizing agent, and HPLCRI has been presented. The MIR-PLS method is applicable to determine individual sugars: glucose, fructose, sucrose, and maltose, with good precision and accuracy. The HPLC-RI method is applicable to determine individual sugars: glucose, fructose, and sucrose, without the matrix effect. The HPLCUV method is applicable to determine only glucose but not other sugars. The sulfuric acid method is applicable to determine total sugar with good precision and accuracy. The amount of individual sugars in Ethiopian traditional fermented alcoholic beverages was determined by using the 
HPLC-RI method, and the total sugar was determined by using the sulfuric acid method. The sugar contents in the Ethiopian fermented alcoholic beverages are comparable with those in the commercial beverages. The differences in the level of sugars in the different types of traditional fermented beverages are due to the variation in the composition of the raw materials, preparation process, and fermentation time used in the traditional fermented beverages.

\section{Data Availability}

The data used to support the findings of this study are available from the corresponding author upon request.

\section{Conflicts of Interest}

The authors declare that they have no conflicts of interest.

\section{Acknowledgments}

The authors express their gratitude to the Department of Chemistry, Addis Ababa University, Ethiopia, for providing the laboratory facilities. Ayalew Debebe is thankful to Haramaya University, Ethiopia, for sponsoring his $\mathrm{PhD}$ study.

\section{References}

[1] D. B. Gomis, D. M. Tamayo, and J. M. Alonso, "Determination of monosaccharides in cider by reversed-phase liquid chromatography," Analytica Chimica Acta, vol. 436, no. 1, pp. 173-180, 2001.

[2] J. H. Ko, H. Huang, G. W. Kang, and W. J. Cheong, "Simultaneous quantitative determination of monosaccharides including fructose in hydrolysates of yogurt and orange juice products by derivatization of monosaccharides with $p$-aminobenzoic acid ethyl ester followed by HPLC," Bulletin of the Korean Chemical Society, vol. 26, no. 10, pp. 1533-1538, 2005.

[3] F. Momenbeik and J. H. Khorasani, "Analysis of sugars by micellar liquid chromatography with UV detection," Acta Chromatographica, vol. 16, pp. 58-69, 2006.

[4] S. Chandraju, R. Mythily, and C. S. Chidan Kumar, "Extraction, isolation and identification of sugars from banana peels (Musa sapientum) by HPLC coupled LC/MS instrument and TLC analysis," Journal of Chemical and Pharmaceutical Research, vol. 3, no. 3, pp. 312-321, 2011.

[5] L. C. Anyika, S. I. Okonkwo, and E. N. Ejike, "Comparative analysis of monosaccharide and disaccharide using different instrument refractometer and polarimeter," International Journal of Research in Chemistry and Environment, vol. 2, no. 4, pp. 270-274, 2012.

[6] C. S. Chidan Kumar, R. Mythily, S. Chandraju, and R. Venkatachalapathi, "Analysis of sugar components extracted from pumpkin (Cucurbita pepo) peels, research \& reviews," Journal of Food Science and Technology, vol. 1, no. 3, pp. 1-6, 2012.

[7] A. Skalska-Kaminska, G. Matysik, M. Wojciak-Kosior, H. Donica, and I. Sowas, "Thin-layer chromatography of sugars in plant material,” Annales, vol. 22, pp. 17-24, 2009.

[8] F. J. Rambla, S. Garrigues, and M. Guardia, "PLS-NIR determination of total sugar, glucose, fructose and sucrose in aqueous solutions of fruit juices," Analytica Chimica Acta, vol. 344, no. 1-2, pp. 41-53, 1997.
[9] L. Gutierrez, A. Zapata, L. Co1l, and C. Diez, "Analytical study of the mineral and sugar fractions of peach liqueurs," Food Chemistry, vol. 54, no. 1, pp. 113-117, 1995.

[10] P. Lehtonen and R. Hurme, "Liquid chromatographic determination of sugars in beer by evaporative light scattering detection," Journal of The Institute of Brewing, vol. 100, no. 5, pp. 343-346, 1994.

[11] M. Karkacier, M. Erbas, M. K. Uslu, and M. Aksu, "Comparison of different extraction and detection methods for sugars using amino-bonded phase HPLC," Journal of Chromatographic Science, vol. 41, no. 6, pp. 331-333, 2003.

[12] A. A. Albalasmeh, A. A. Berhe, and T. A. Ghezzehei, "A new method for rapid determination of carbohydrate and total carbon concentrations using UV spectrophotometry," Carbohydrate Polymers, vol. 97, no. 2, pp. 253-261, 2013.

[13] W. Zhang, H. He, and X. Zhang, "Determination of neutral sugars in soil by capillary gas chromatography after derivatization to aldononitrile acetates," Soil Biology and Biochemistry, vol. 39, no. 10, pp. 2665-2669, 2007.

[14] A. I. Ruiz-Matute, O. Hernandez-Hernandez, S. RodriguezSanchez, M. L. Sanz, and I. Martinez-Castro, "Derivatization of carbohydrates for GC and GC-MS analyses," Journal of Chromatography B, vol. 879, no. 17-18, pp. 1226-1240, 2011.

[15] D. B. Gomis, D. M. Tamayo, and J. J. Mangas Alonso, "Evolution of sugars in cider brandy aged in oak barrels: A contribution to its characterization," Journal of Agriculture and Food Chemistry, vol. 51, no. 4, pp. 923-926, 2003.

[16] F. Shen, Y. Ying, B. Li, Y. Zheng, and J. Hu, "Prediction of sugars and acids in chinese rice wine by mid-infrared spectroscopy," Food Research International, vol. 44, no. 5, pp. 1521-1527, 2011.

[17] S. Cortacero-Ramırez, A. Segura-Carretero, C. Cruces-Blanco, C. M. Hernainz-Bermudez, and A. Fernandez-Gutierrez, "Analysis of carbohydrates in beverages by capillary electrophoresis with precolumn derivatization and UV detection," Food Chemistry, vol. 87, no. 3, pp. 471-476, 2004.

[18] C. S. Chidan Kumar, S. Chandraju, R. Mythily, T. Ahmad, and N. M. Made Gowda, "Extraction of sugars from black gram peels by reversed-phase liquid chromatography systems and identification by TLC and mass analysis," Advances in Analytical Chemistry, vol. 2, no. 4, pp. 32-36, 2012.

[19] N. P. Evmiridis, N. K. Thanasoulias, and A. G. Vlessidis, "Determination of glucose and fructose in mixtures by a kinetic method with chemiluminescence detection," Analytica Chimica Acta, vol. 398, no. 2-3, pp. 191-203, 1999.

[20] A. Debebe, B. S. Chandravanshi, and M. Redi-Abshiro, "Total contents of phenolics, flavonoids, tannins and antioxidant capacity of selected traditional Ethiopian alcoholic beverages," Bulletin of the Chemical Society of Ethiopia, vol. 30, no. 1, pp. 27-37, 2016.

[21] A. Debebe, A. Anberbir, M. Redi-Abshiro et al., "Alcohol determination in distilled alcoholic beverages by liquid phase Fourier transform mid-infrared and near-infrared spectrophotometers," Food Analytical Methods, vol. 10, pp. 172-179, 2017.

[22] A. Debebe, M. Redi-Abshiro, and B. S. Chandravanshi, "Non-destructive determination of ethanol levels in fermented alcoholic beverages using Fourier transform midinfrared spectrometry," Chemistry Central Journal, vol. 11, no. $1,2017$.

[23] A. Debebe, S. Temesgen, M. Redi-Abshiro, and B. S. Chandravanshi, "Partial least square-ultra violet near infrared spectrometric determination of ethanol in distilled alcoholic beverages and its comparison with reference 
method, gas chromatography," Bulletin of the Chemical Society of Ethiopia, vol. 31, no. 2, pp. 201-209, 2017.

[24] A. Debebe, B. S. Chandravanshi, and M. Redi-Abshiro, "Assessment of essential and non-essential metals in Ethiopian traditional fermented alcoholic beverages," Bulletin of the Chemical Society of Ethiopia, vol. 31, no. 1, pp. 17-30, 2017.

[25] G. Debebe, "Determination of ethanol level in beverages," Master Thesis, Addis Ababa University, Addis Ababa, Ethiopia, 2006.

[26] T. Yohannes, F. Melak, and K. Siraj, "Preparation and physicochemical analysis of some Ethiopian traditional alcoholic beverages," African Journal of Food Science, vol. 7, no. 11, pp. 399-403, 2013.

[27] B. Bahiru, T. Mehari, and M. Ashenafi, "Chemical and nutritional properties of "Tej", an indigenous Ethiopian honey wine: variations within and between production units," The Journal of Food Technology in Africa, vol. 6, no. 3, pp. 104-108, 2001.

[28] K. Abegaz, F. Beyene, T. Langsrud, and J. A. Narvhus, "Indigenous processing methods and raw materials of borde, an Ethiopian traditional fermented beverage," The Journal of Food Technology in Africa, vol. 7, no. 2, pp. 59-64, 2002.

[29] M. Ashenafi, "A review on the microbiology of indigenous fermented foods and beverages of Ethiopia," Ethiopian Journal of Biological Sciences, vol. 5, no. 2, pp. 189-245, 2006.

[30] R. A. Abawari, "Indigenous processing methods and raw materials of Keribo: An Ethiopian traditional fermented beverage," Journal of Food Resource Science, vol. 2, no. 1, pp. 13-20, 2013.

[31] T. Munegumi and A. Goto, "Reversed-phase highperformance liquid chromatography of disaccharides labeled by 4-aminobenzoic acid ethyl ester," Der Pharma Chemica, vol. 6, no. 1, pp. 248-252, 2014.

[32] F. J. Rambla, S. Garriguesa, N. Ferrerb, and M. Guardiaa, "Simple partial least squares-attenuated total reflectance Fourier transform infrared spectrometric method for the determination of sugars in fruit juices and soft drinks using aqueous standards," Analyst, vol. 123, pp. 277-281, 1998.

[33] L. F. Leopold, N. Leopold, H.-A. Diehl, and C. Socaciu, "Quantification of carbohydrates in fruit juices using FTIR spectroscopy and multivariate analysis," Spectroscopy, vol. 26, no. 2, pp. 93-104, 2011.

[34] A. Moghimi, M. H. Aghkhani, A. Sazgarnia, and M. Sarmad, "Vis/NIR spectroscopy and chemometrics for the prediction of soluble solids content and acidity $(\mathrm{pH})$ of Kiwi fruit," Biosystems Engineering, vol. 106, no. 3, pp. 295-302, 2010.

[35] J. Irudayaraj and J. Tewari, "Simultaneous monitoring of organic acids and sugars in fresh and processed apple juice by Fourier transform infrared-attenuated total reflection spectroscopy," Applied Spectroscopy, vol. 57, no. 12, pp. 15991604, 2003.

[36] A. Nose and M. Hojo, "Hydrogen bonding of water-ethanol in alcoholic beverages," Journal of Bioscience and Bioengineering, vol. 102, no. 4, pp. 269-280, 2006.

[37] R. R. Madrera and B. S. Valles, "Determination of volatile compounds in cider spirits by gas chromatography with direct injection," Journal of Chromatographic Science, vol. 45, no. 7, pp. 428-434, 2007

[38] M. M. Sanagi, S. L. Ling, Z. Nasir, W. A. W. Ibrahim, and A. A. Naim, "Comparison of signal-to-noise, blank determination, and linera regression methods for the estimation of detection and quantification limits for volatile organic compounds by gas chromatography," Journal of AOAC International, vol. 92, no. 6, pp. 1833-1838, 2009.
[39] M. Jurková, Č. Pavel, K. Štěrba, and J. Olšovská, "Determination of total carbohydrate content in beer using its pre-column enzymatic cleavage and HPLC-RI," Food Analytical Methods, vol. 7, no. 8, pp. 1677-1686, 2014.

[40] Z. Hodžić, B. Banjanin, and J. Sadadinović, "Fermentable carbohydrates determination in different worts by HPLC-RI," Journal of Engineering, vol. 1, pp. 105-110, 2008.

[41] B. Matsuhiro, R. Torres, E. A. Zúñiga, M. J. Aguirre, L. Mendoza, and M. Isaacs, "Determination of low molecular weight carbohydrates in cabernet sauvignon red wines," Journal of the Chilean Chemical Society, vol. 54, no. 4, pp. 405-407, 2009.

[42] H. Kelebek, S. Selli, A. Canbas, and T. Cabaroglu, "HPLC determination of organic acids, sugars, phenolic compositions and antioxidant capacity of orange juice and orange wine made from a Turkish Cv. Kozan," Microchemical Journal, vol. 91, no. 2, pp. 187-192, 2009.

[43] M. A. Augustin and K. L. Khor, "Determination of sugars in soft drinks by high performance liquid chromatography," Pertanika, vol. 9, no. 1, pp. 119-123, 1986.

[44] A. Sapcanin, G. Jancan, R. Jadric et al., "Determination of sugar content in flavored waters," Bulletin of Chemical Technology of Bosnia and Herzegovina, vol. 41, pp. 29-32, 2013. 

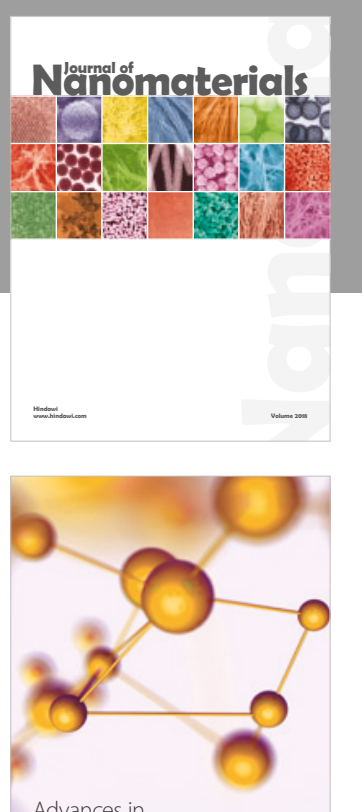

Physical Chemistry
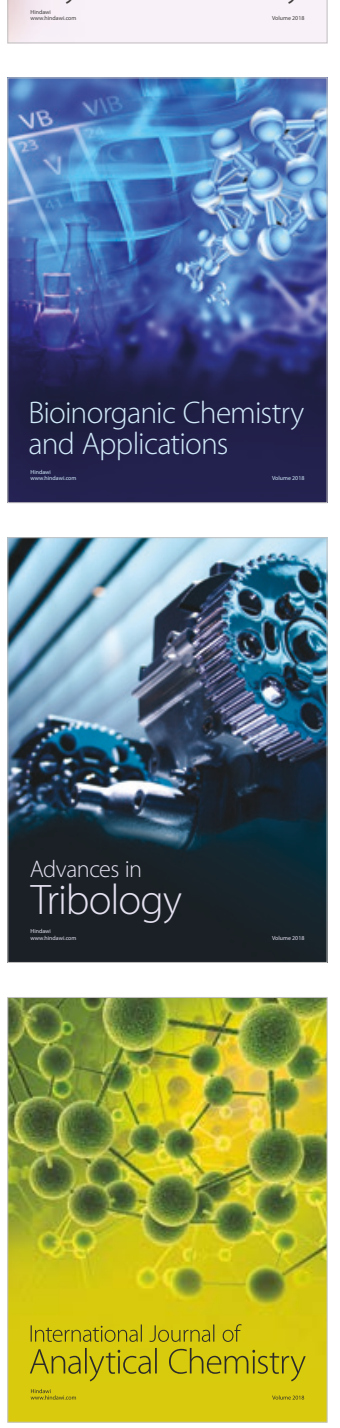

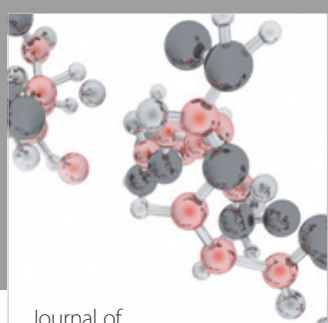

Analytical Methods

in Chemistry

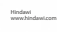

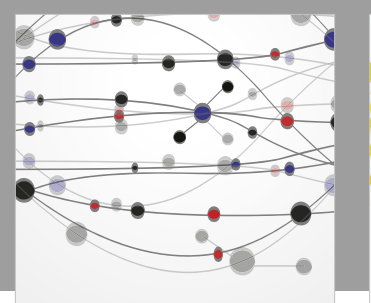

The Scientific World Journal

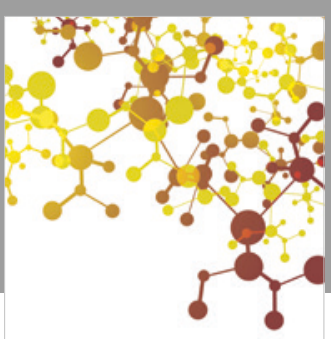

Journal of

Applied Chemistry
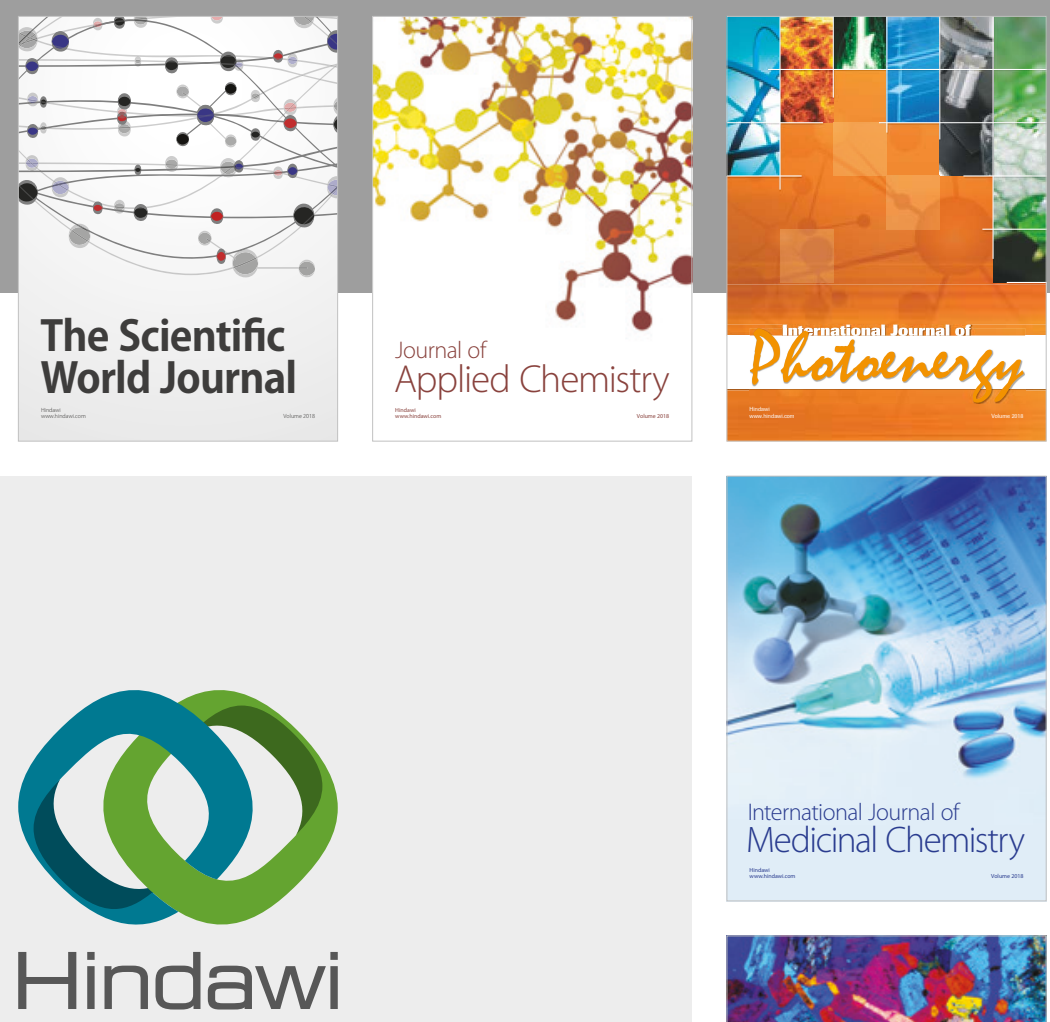

Submit your manuscripts at

www.hindawi.com
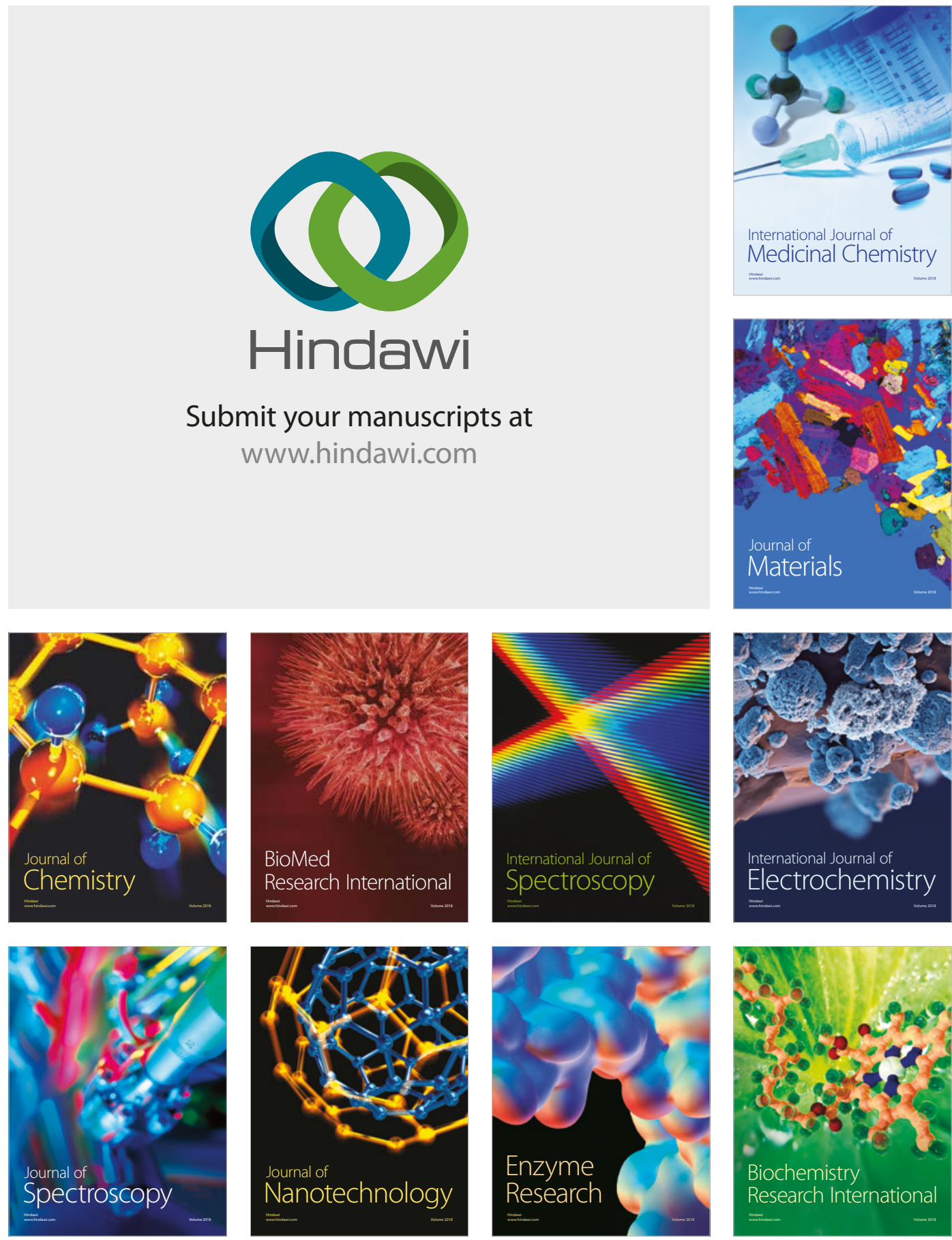
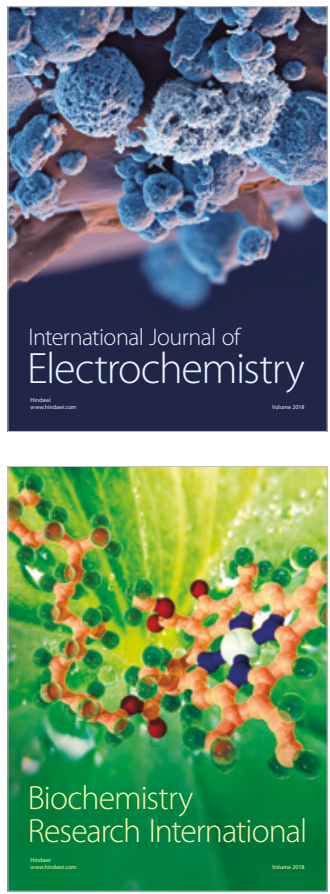